\title{
The accuracy and effectiveness of self-gating signals in free-breathing 3D cardiac cine MRI
}

\author{
Shuo $\mathrm{Li}^{1,2^{*}}$, Yanchun Zhu', Jie Yang ${ }^{1}$, Yaoqin Xie', Song Gao ${ }^{2}$ \\ From 19th Annual SCMR Scientific Sessions \\ Los Angeles, CA, USA. 27-30 January 2016
}

\section{Background}

Conventional cardiac cine magnetic resonance imaging (MRI) is typically based on the segmented data acquired by breath-hold 2D balanced steady-state free procession (SSFP) pulse sequence [1]. However, the slice misregistration caused by the variation of breath holding positions could compromise the effectiveness of 2D SSFP, and breath-hold makes it difficult for pediatric patients or patients who suffer from congestive heart failure to cooperate [2]. Recently, respiratory and cardiac selfgated free-breathing (FB) cardiac cine MRI have been proposed for overcoming these barriers [3]. This approach could provide similar image quality and functional measurements without using electrocardiographic (ECG) or any peripheral equipment compared with 2D SSFP. However, the precision comparison between the self-gating signals and the external signals needs to be studied systematically.

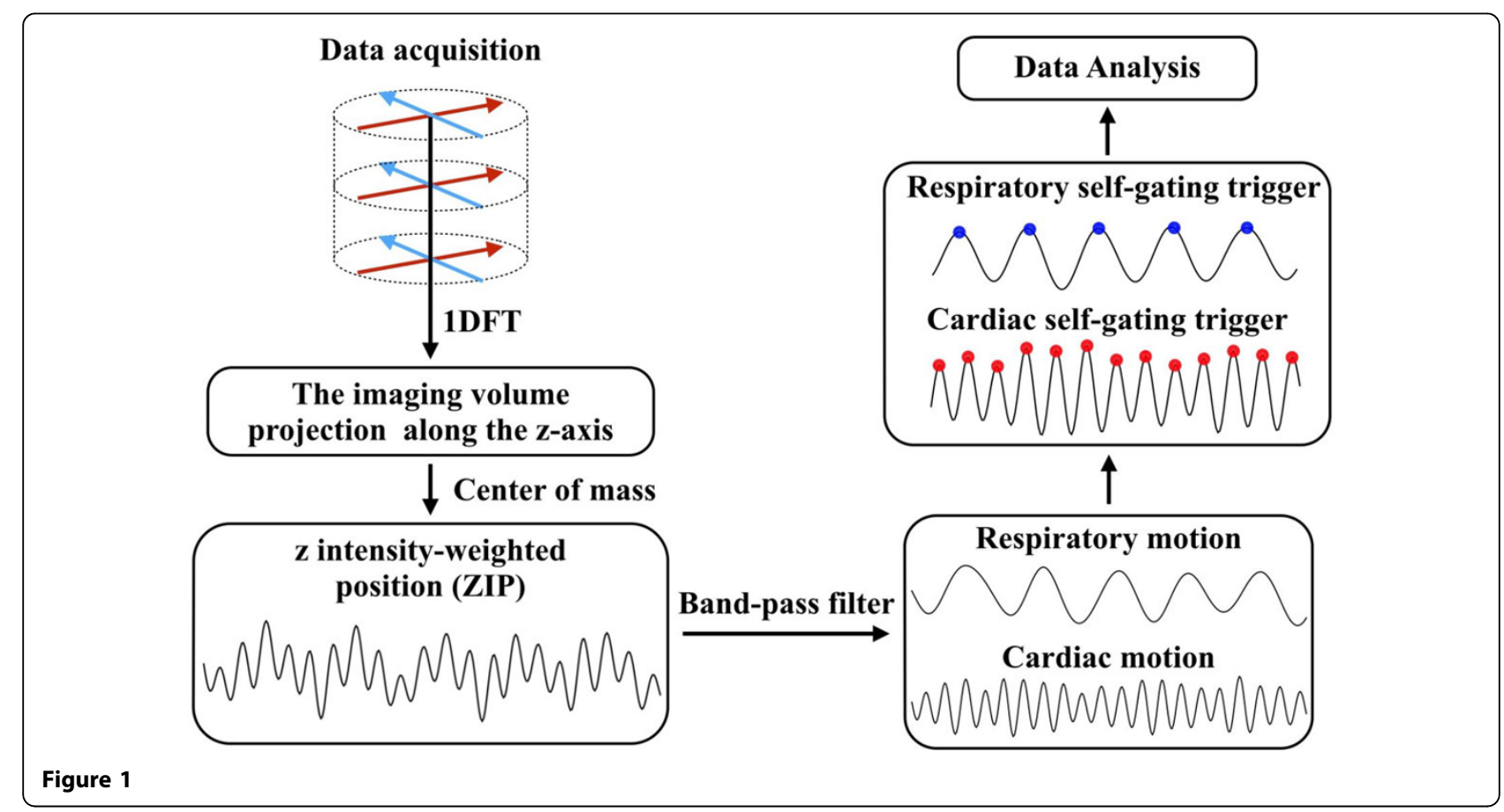

'Shenzhen Institutes of Advanced Technology, Chinese Academy of

Sciences, Shenzhen, China

Full list of author information is available at the end of the article 
Table 1 The cardiac and respiratory cycle duration obtained with peripheral equipment and self-gated FB SSFP technique.

\begin{tabular}{ccc}
\hline & Cardiac cycle duration $(\mathbf{m s})$ & Respiratory cycle duration (ms) \\
\hline Peripheral equipment & $750.5 \pm 98.0$ & $2748.7 \pm 201.5$ \\
Self-gated FB SSFP & $750.5 \pm 98.1$ & $2748.5 \pm 200.1$ \\
Correlation $(p=0)$ & $0.60 \pm 0.14$ & $0.64 \pm 0.13$ \\
T-test $P$ value $(H=0)$ & $0.98 \pm 0.02$ & $0.98 \pm 0.02$ \\
\hline
\end{tabular}

\section{Methods}

A self-gated FB 3D SSFP cine pulse sequence with hybrid radial $k$-space sampling based on golden angle was used for extracting the cardiac self-gating (CSG) and respiratory self-gating (RSG) signals. The peak positions of CSG/RSG signal curves were regarded as the CSG/RSG triggers. Respiratory bellows (RB) triggers and ECG triggers recorded by the peripheral equipment were used as the external triggers for comparison. The flow chart of this study is shown in Figure 1. The cardiac imaging was performed in 13 healthy volunteers on a 1.5T GE HDx scanner (maximum gradient amplitude $33 \mathrm{mT} / \mathrm{m}$, slew-rate $120 \mathrm{mT} / \mathrm{m} / \mathrm{s}$, Excite 14M5 software; GE Healthcare, Waukesha, WI, USA). The study was approved by the local institutional review board and written informed consent was obtained from all subjects prior to enrolment. An eight-channel cardiac phased-array coil was used for signal reception. The cine imaging parameters were set as follows: $\mathrm{TR} / \mathrm{TE}=3.5 / 1.3 \mathrm{~ms}$, flip angle $=40^{\circ}, \mathrm{BW}= \pm 125$ $\mathrm{kHz}$, slice thickness $=7 \mathrm{~mm}$ (no gap), number of slices = 12 , number of profiles $=5000$, temporal resolution $=42$ $\mathrm{ms}$, total acquisition time $=4.5$ minutes.

\section{Results}

The mean heart rates are 81.302 (ECG) and 81.304 (CSG) bpm (beats per minute). The mean breathing rates are 21.934 (RB) and 21.933 (RSG) bpm (breaths per minute). The CSG and RSG cycle durations comparison, the correlation coefficient and the $\mathrm{P}$ value of twotailed t-test are presented in Table 1. The RMSD between cardiac and respiratory cycle durations are 36.6 $\pm 8.8 \mathrm{~ms}$ and $328.1 \pm 117.4 \mathrm{~ms}$. The trigger time delay are $486.6 \pm 78.2 \mathrm{~ms}$ (cardiac) and $-309.0 \pm 181.1 \mathrm{~ms}$ (respiratory).

\section{Conclusions}

Self-gating signals can well synchronize the cardiac and respiratory motion. It has excellent correlations with the external signals and the RMSD is acceptable. The t-test shows that there is no significant difference between two methods. Future study will focus on the comparison of self-gating signals extraction algorithms.
Authors' details

'Shenzhen Institutes of Advanced Technology, Chinese Academy of Sciences, Shenzhen, China. ${ }^{2}$ Peking University Health Science Center, Beijing, China.

Published: 27 January 2016

\section{References}

1. Hudsmith LE, et al: J Cardiovasc Magn R 2005, 7(5):775-782.

2. Sievers B, et al: Acta Cardiol 2011, 66:349.

3. Liu J, et al: Magn Reson Med 2010, 63:1230.

doi:10.1186/1532-429X-18-S1-P10

Cite this article as: Li et al:: The accuracy and effectiveness of selfgating signals in free-breathing 3D cardiac cine MRI. Journal of Cardiovascular Magnetic Resonance 2016 18(Suppl 1):P10.
Submit your next manuscript to BioMed Central and take full advantage of:

- Convenient online submission

- Thorough peer review

- No space constraints or color figure charges

- Immediate publication on acceptance

- Inclusion in PubMed, CAS, Scopus and Google Scholar

- Research which is freely available for redistribution

Submit your manuscript at www.biomedcentral.com/submit 